\title{
DESIGN CONTRIBUTION TO CONSUMERS KNOWLEDGE REGARDING HEALTHIER AND MORE SUSTAINABLE NUTRITIONAL CHOICES AT THE GROCERY STORE
}

\author{
Egle JUODZIUKYNAITE \\ Oslo Metropolitan University
}

\begin{abstract}
In Norwegian grocery stores, consumers encounter many accreditation labels. However, these rarely contribute to healthier or more environmentally friendly nutritional choices. This master's study analyses how product design may contribute to consumers knowledge regarding healthier and more sustainable nutritional choices at the grocery store. This paper contributes with a Norwegian perspective. The study also discusses the role of food and nutrition literacy as well as potential improvements in the educational system. Qualitative research methods such as empirical data collection, literature review and semi-structured interviews with an expert have been used to explore the field and gain insights. The raw data was collected using the empirical data collection method. The literature review laid the theoretical foundation for the paper, and three case studies were chosen. By analysing these cases, three possible product design concepts for the research question were identified: dynamic food labels, traffic light labels and visual clues. Finally, the concept mapping tool was used to visualise this new framework so that it can be used to strengthen cross-disciplinary communication between product designers and nutritionists. Findings from this study show a lack of cross-disciplinary collaboration between nutritionists and designers. This study has focused on understanding the problem area and revealing product design opportunities in the field. Future research may want to further explore the interdisciplinary problem area and consider involving a cross-disciplinary team.
\end{abstract}

Keywords: Product design, healthy nutrition, sustainable nutrition, labelling, grocery store

\section{INTRODUCTION: INFORMATION OVERLOAD FOR CONSUMERS}

Technological and societal changes have affected the way food is promoted, sold, and consumed. The number of products has increased significantly, along with the amount of information on the packaging. Some information and labelling is required by law, some is optional, and some is part of a marketing strategy. Globally, there are many different practices regarding the use of front-of-pack information. This paper will contribute with a Norwegian perspective. However, similar local studies should be conducted in other countries in order to understand the overall situation and to find the best solutions.

According to the Norwegian Consumer Council, more than 100 different accreditation labels can be found in a regular grocery store [1]. However, informing through labelling in this way does not seem to contribute to healthier or environmentally friendly nutritional choices by the average consumer. Conversely, a large number of colourful symbols in addition to other front-of-pack information may seem overwhelming. Many of these labels have a commercial look, and few of them inform consumers about what they represent or to what extent a product with a particular label fulfils the accreditation requirements.

According to the expert group behind the report 'Healthier food environments in Norway: Assessment of current policy and recommendations for further efforts' (author's translation), the occurrence of obesity cases is increasing in the Norwegian population [2]. In addition to that, food accounts for over a quarter (26\%) of global greenhouse gas emissions [3]. This indicates that something has to be done to help people to make both healthy and sustainable choices. This master's study looks at how design methods can be used to help consumers make more informed choices. 


\section{BACKGROUNDS: PRODUCT DESIGN EVOLUTION AND NUTRITION}

\subsection{Product design evolution}

The product design profession is constantly changing. Early product designers came from many different backgrounds and they were qualified to a design profession because of their artistic, decorative and constructive abilities [4]. The field of product design now requires other kinds of skills, such as listening, asking, understanding, and drafting new possibilities. The world of product design has evolved from studying things to studying humanity [4]. New product designers tend to be good at understanding complex issues, identifying core problems and selecting appropriate goals [4]. Furthermore, product designers tend to have the necessary tools to analyse information in order to find the best solution to satisfy the needs of all the parties involved in the system.

Design is an ever evolving field which ultimately reflects society [4]. In our technological age, with many complex challenges to handle, product designers play a significant role. The design of objects today is no longer restricted to form, function, material and production [5]. Products today tend to be more complex and more often part of a bigger system with multiple connections. Therefore, to make products that are relevant to society, product designers need to understand the wider, overall perspective. Fortunately, product designers do not stand alone in designing new products. The technological age has given rise to a greater need for and understanding of cross-disciplinary collaboration. While working together with other disciplines, product designers have the possibility to achieve a better understanding of the core of the problem. Examples of cross-disciplinary collaboration models can be found in many sectors [4], such as in communication technology sector, between technology experts and designers from different fields, or in the healthcare sector.

\subsection{Challenges regarding to nutrition}

Climate change and diet-related diseases in the population are some of the most debated topics today. People are informed about these issues in the media. Nevertheless, it seems that society does not know how to contribute to making the situation better. What is needed to help society overcome these challenges?

Food production, transportation and storage of food waste contribute to greenhouse gas emissions and, thus, to climate change. This accounts for 70 per cent of all water consumption [6], which means that society needs to find more climate-friendly ways to distribute food. However, how do we get people to care about climate changes that they do not see? One way is to link it to something that has a direct impact on them, such as a healthy diet.

Both climate and diet-related challenges have a major negative impact on society. To succeed in combating these, they should be seen in conjunction with each other. The expert group behind the report 'Healthier food environments in Norway: Assessment of current policy and recommendations for further efforts' states that: 'A change in diet will both provide a significant health benefit and may help reduce greenhouse gas emissions.' [2].

In this project, the Norwegian grocery store was chosen as the core of the system. It is a meeting point between the other sub-systems: consumers, suppliers, manufacturers, and the Norwegian authorities. The research question was, therefore, as follows: How can product design contribute to consumers knowledge regarding healthier and more sustainable choices at the Norwegian grocery store?

\section{METHODS: UNDERSTANDING THE CONTEXT}

\subsection{Methodological triangulation and qualitative research methods}

In this study, methodological triangulation was used to map the richness of the field by studying it from more than one standpoint and by using several data collection methods [7]. Research methods such as qualitative data collection through observation, a thematic literature review and semi-structured interviews were used to explore the field and to gain new insights. According to Muratovski, such qualitative methods are suitable for gaining an in-depth understanding of a particular problem [4]. Observation was used to collect the empirical data at the very beginning of the project [8]. A thematic literature review was conducted to study what is already known and what has already been done in the field relevant to the research question, as well as to identify areas that need further investigation [4]. Semi-structured interviews were chosen for more natural conversation, using a few pre-written open questions to allow the interviewees to add their thoughts continuously [9]. Finally, all the findings were 
visualised using a concept mapping tool. This method helped identify the main findings from all the above-mentioned methods and to analyse the information collected [10]. Data collection and analysis of the findings were carried out in parallel throughout the research process.

\section{FINDINGS: LACK OF COMPETENCE}

\subsection{Empirical data collection through observation: Research in the field}

Empirical data collection consisted of observations made in a local grocery store and brief discussions conducted with the employees. This method aimed to investigate how easy or complex it is to buy food that is both healthy and environmentally friendly.

First, an examination was conducted of what kind of environmental and health-related labels were placed on various food items. A large variety of labels was observed, some of them well known, such as the Keyhole label and the EU Ecolabel. However, many of the labels were less familiar or difficult to understand. Examples were found of misleading labels used as marketing ploys.

Another observation made was the lack of knowledge among grocery store employees, who were not required to know about the nutritional content or environmental impacts of the items on sale. This limits the help available to customers while doing their daily shopping.

\subsection{Literature review: Existing knowledge and case studies}

Relevant and updated literature from 2019 and 2020 was reviewed to gain more information about the state of knowledge in the chosen area of interest. The chosen type of literature review was thematic. The purpose of this type of review is to examine various perspectives related to the question [4]. However, the literature review only provided a snapshot of the current state of knowledge in the field, since it is continuously changing [4]. The main keywords used in the literature search included: 'product design', 'design', 'nutrition', 'food', 'sustainable food' and 'healthy'. Emphasis was placed on literature that focused on both environmental and nutritional information. The Web of Science database was used for the literature search.

The reviewed literature contained the following articles: 'The effect of dynamic food labels with realtime feedback on diet quality' [11], 'Show me more! The influence of visibility on sustainable food choices' [12], 'Traffic light labelling of meals to promote sustainable consumption and healthy eating' [13] and 'Healthier food environments in Norway: Assessment of current policy and recommendations for further efforts' [2]. The reviewed literature laid the theoretical foundation for the paper. Three articles included case studies that contributed to learning from examples of solutions relevant to the research question [14]. In this study, the focus was specifically placed on an article that was published in autumn 2020 and that attracted wide attention from the Norwegian authorities and media. Furthermore, Liv Elin Torheim, Professor of Public Health Nutrition, who has led the research project behind the report, contributed to this master's study by being interviewed.

\subsubsection{Case study 1-Dynamic food labels}

The first case study investigated the effect of dynamic food labels with real-time feedback [11]. The chosen arena for analysis was an online grocery store. The dynamic food labels consisted of front-ofpack (FOP) labels with information about nutrition combined with real-time feedback on the overall nutritional quality. The results from experiments conducted by this study indicated that the use of dynamic food labels with real-time feedback had a significant impact on the nutritional quality and had decreased the total amount of sugar per shop. The proposed FOP labels had a nudging effect on a behavioural change towards a healthier nutritional choice. Even though this study had no direct environmental focus, the proposed solution also has the potential to implement sustainability elements.

\subsubsection{Case study 2 - The influence of visibility}

The second case study investigated the importance of visual clues in an in-store environment [12]. In this study, experts performed a field experiment in a butchery located in a supermarket. The size of the display area and the quantity of poultry products on display were increased, while the size of the display area and the quantity of less sustainable meat products such as pork, beef and prepared meat dishes were decreased. During the nudging intervention, the sales of poultry products increased, while the sales of less sustainable meat products did not change. When the size of the display was reverted to its original size, the sales of poultry products decreased again. This experiment indicates that by changing the size 
of the display area and the number of products displayed it is possible to create a shift in consumers' purchase behaviour. However, more research is needed to find out what might reduce purchases of less sustainable meat products.

\subsubsection{Case study 3 - Traffic light labelling}

This study tested the effect of traffic light labelling attached to different meal options as an indication of their impact on both the environment and health [13]. The chosen arena for analysis was a hypothetical simulated canteen. The results from the study show that, compared to baseline, the presence of traffic light labels led to positive shifts towards lower carbon emissions and lower calorific content meals. The study also found that the best effect can be achieved not by using traffic light labels alone, but by combining these with additional information. Even though this study focused on a canteen, the solution might also be implemented in the grocery store context. The study focused on both the environmental and health aspects, something which few other studies have done before.

\subsection{Semi-structured interviews with an expert}

To gain a deeper understanding of the theory and to get a professional view on the chosen topic, two semi-structured interviews were conducted with Professor Liv Elin Torheim, a professor of public health nutrition at OsloMet - Oslo Metropolitan University. She is also one of the experts behind the report 'Healthier food environments in Norway' published last year. The semi-structured form of the interviews provided an opportunity to uncover areas and theories that were not identified through the empirical data collection and literature review. The first interview was more general and consisted of an open discussion around the topic of nutrition, theories behind the previously mentioned report, as well as a brief introduction to the design profession. Torheim referred to some relevant research and case studies that were relevant for this project.

The goals for the second interview were to go more in-depth in the areas touched on during the first interview and to ask more concrete questions. In this interview, Professor Torheim explained some of the challenges to eating healthily, such as being more expensive, and because it takes more time to prepare healthy food. Additionally, grocery stores are often designed to push consumers into unhealthy and unsustainable directions by, for example, using appealing packaging or placing products rich in sugar and salt in the add-on sales areas close to the checkouts. This interview strengthened the findings from the empirical data collection in the field. Food chains use design methods to find out what buttons they need to push in order to make us buy their products. Torheim proposed that nutritionists need to use the same kind of tricks to nudge consumers towards more sustainable and healthier nutritional choices. More involvement of design expertise in the nutritional field may be a solution.

\section{DISCUSSIONS: PRODUCT DESIGN CONTRIBUTION}

\subsection{Products as part of complex systems}

Data collected during the observations in the grocery store and the literature review show that despite the large amount of different labelling on food items, customers still have issues connected to choosing both healthy and environmentally friendly foods. When several organisations create their own labels, consumers can become confused and overwhelmed. In addition, the interviews with Professor Torheim show that grocery stores are not designed to contribute to sustainable food choice. Conversely, graphic design tools such as visual presentation on products is being used with the goal of selling more and making money. However, there seems to be a need for more product design involvement in the Norwegian grocery store to help consumers make higher-quality nutritional choices.

Products are complex and are often a part of a larger system. Before products arrive at the grocery store, they have to be designed, tested, manufactured, packed, transported, in some cases advertised, before being placed on the shelf.

Many people, sectors and even countries are involved in this system. For a product designer it is more important than ever to understand the whole system in order to make products that are easy and cheap to produce and that deliver profit, meet sustainability goals, comply with regulations, are convenient to use and that look attractive to consumers. In addition to this, product designers have to take ethical considerations into account and think about the usage phase and the end of the product's life. Product design is about much more than just designing a single product. 


\subsection{Product design contribution to the field}

During the interviews, Professor Torheim commented that nutritionists 'do not know what expertise designers have and what can they be used for'. Additionally, none of the analysed case studies from the literature review mentioned designers in their reports. However, there are many possibilities for a product designer to contribute to positive changes when it comes to consumers choosing both healthy and sustainable food items in grocery stores.

Through the case studies, three possible concepts were found: dynamic food labels, traffic light labels and visual clues. These concepts form the foundation for a possible product design solution. Elements from these concepts could be combined in order to create the best solution. The concept map bellow (Figure 1) visualises the connections between the above-mentioned concepts. A visualisation tool was chosen to conceptualise the framework [10] and is intended to be used to initiate cross-disciplinary communication between product designers and nutritionists. Product design was placed in the centre of the map to show that product design expertise can be used when implementing these solutions as well as when developing new solutions based on findings from these case studies.

In the interviews with Professor Torheim, some examples of projects where product designers and nutritionists could collaborate were discussed, such as developing the appearance of a new type of packaging, reorganising grocery stores and analysing the entire customer journey from meal planning to entering the store. These examples were placed in the concept map below product design to illustrate the ways in which they might contribute.

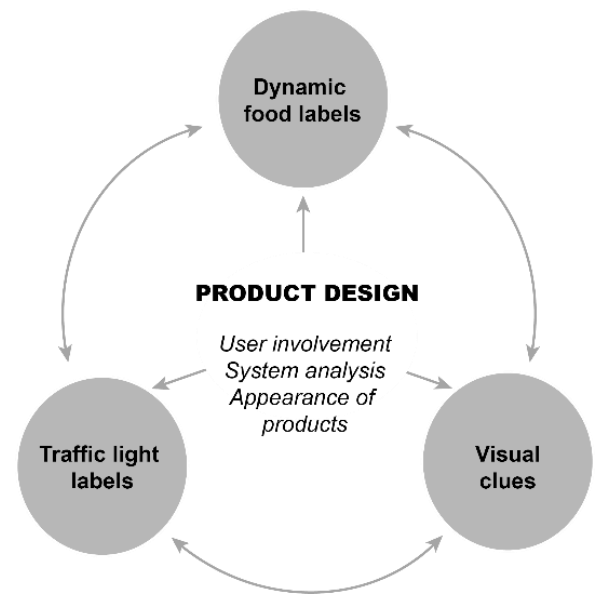

Figure 1. Concept map - visualisation of a new framework

\subsection{Need for changes in design education}

Grocery items such as prepared meals and pizzas often have packaging with space for illustrations and necessary information. However, grocery items which nutritionists want us to consume more of, such as fish, vegetables, and fruit, do not come with instructions on how to prepare them. Professor Torheim sees a need for food and nutrition literacy. The educational system should contribute to increasing interdisciplinary knowledge in order to promote healthy food making and healthy food eating. Without this type of knowledge, consumers might face many barriers when it comes to changing to a healthier and more sustainable diet. The product designer can help shift the focus to food and nutrition literacy in the educational system with the help of nutritional experts. Many design education programmes have traditionally been modelled on fine and applied arts [4]. However, cross-disciplinary research, technological development and critical thinking in the field of design are creating new opportunities for the new generation of designers [4]. These new product designers can be used in several kinds of projects because of the skillsets they have in analysing complex systems and in using a holistic design thinking methodology and a user-centred approach. Therefore, the professional field of design and design education programmes should enhance communication with other disciplines regarding the new skills and qualities the product design profession can offer, as well as how designers can contribute to different projects.

\section{CONCLUSIONS AND SUGGESTIONS FOR FUTURE DIRECTION}

Findings from the case studies and the semi-structured interviews show a lack of cross-disciplinary collaboration. Both healthy eating and sustainability are complex issues, and contributions from 
different fields of expertise are needed to find the best solutions. By involving product designers in their work, nutritionists may develop solutions that are more appealing to consumers and find creative ways to engage healthy and environmentally friendly food consumption. However, a better understanding of the different professions and their respective terminologies is needed to achieve more cross-disciplinary collaboration. The framework presented in this paper connects existing concepts - dynamic food labels, traffic light labels and visual clues - and suggests using product design expertise when implementing these or new solutions for healthy food consumption.

This pilot study has focused on understanding the problem area and revealing product design opportunities in the field of healthy and sustainable nutrition. However, further research could include closer investigation of what lies behind consumers' food purchasing decisions. Such future research might want to explore the field and problem areas in more depth to conduct similar studies in other countries. A cross-disciplinary approach might be fruitful in further studies of this subject, given the complexity of the field.

\section{ACKNOWLEDGEMENTS}

I would like to acknowledge my supervisor, Arild Berg, Professor in Product Design for his help. I would also like to thank Liv Elin Torheim, Professor of Public Health Nutrition at OsloMet, Finally, I would like to thank my fellow students and the employees at my local grocery store.

\section{REFERENCES}

[1] Forbrukerrådet. Forbrukerrådets Merkeoversikt. Available:

https://www.forbrukerradet.no/merkeoversikten/ [Accessed on 2020, 1 September].

[2] Torheim L. E., Løvhaug A. L., Huseby C. S., Terragni L., Henjum S., and Roos G. Sunnere matomgivelser i Norge: Vurdering av gjeldende politikk og anbefalinger for videre innsats. Oslo Metropolitan University, Oslo, September 2020.

[3] Poore J. and Nemecek T. Reducing food's environmental impacts through producers and consumers. Science, 2018, 360(6392), 987-92.

[4] Muratovski G. Research for Designers: A Guide to Methods and Practice, 2016 (Sage, London).

[5] Stickdorn M. and Schneider J. This is Service Design Thinking, 2011 (John Wiley \& Sons, New Jersey).

[6] FAO. Integrated agriculture water management and health. Food and Agriculture Organization of the United Nations, 2020.

[7] Cohen L., Manion L., and Morrison K. Research methods in education. 2007 (Routledge, Abingdon).

[8] Ogienko N. and Kim A. The empirical data collection and processing as a factor of research activity effectiveness. CBU International Conference on Innovation, Technology Transfer and Education, ISE Research Institute, Vol. 2(0), July 2014, pp. 238-245.

[9] Descombe M. The good research guide for small-scale social research projects, 1998 (Open University Press, Buckingham).

[10] Maxwell J. A. Qualitative Research Design: An Interactive Approach, 2nd ed, 2005 (Sage Publication, Thousand Oaks).

[11] Shin S., van Dam R. M. and Finkelstein E. A. The Effect of Dynamic Food Labels with RealTime Feedback on Diet Quality: Results from a Randomized Controlled Trial. Nutrients, 2020, 12(7), 2158.

[12] Coucke N., Vermeir I., Slabbinck H., and van Kerckhove A. Show Me More! The Influence of Visibility on Sustainable Food Choices. Foods, 2019, 8(6).

[13] Osman M. and Thornton K. Traffic light labelling of meals to promote sustainable consumption and healthy eating. Appetite, 2019, 138, pp. 60-71.

[14] Heale R. and Twycross A. What is a case study? Evidence-Based Nursing, 2017, 21(1) pp. 7-8. 